\title{
EFFECTS OF CARDIOPULMONARY BYPASS ON PROPOFOL PHARMACOKINETICS AND BISPECTRAL INDEX DURING CORONARY SURGERY
}

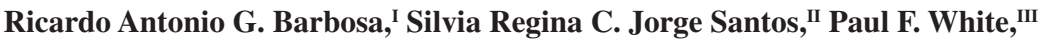

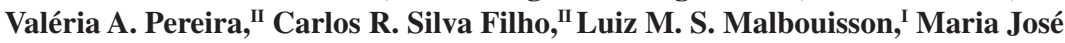 \\ C. Carmona ${ }^{\mathrm{I}}$
}

doi: $10.1590 / \mathrm{S} 1807-59322009000300012$

Barbosa RAG, Santos SRCJ, White PF, Pereira VA, Silva Filho CR, Malbouisson LMS. Effects of cardiopulmonary bypass on propofol pharmacokinetics and bispectral index during coronary surgery. Clinics. 2009;64(3):215-21.

PURPOSE: Cardiopulmonary bypass is known to alter propofol pharmacokinetics in patients undergoing cardiac surgery. However, few studies have evaluated the impact of these alterations on postoperative pharmacodynamics. This study was designed to test the hypothesis that changes in propofol pharmacokinetics increase hypnotic effects after cardiopulmonary bypass.

METHODS: Twenty patients scheduled for on-pump coronary artery bypass graft (group, $n=10$ ) or off-pump coronary artery bypass graft (group, $\mathrm{n}=10$ ) coronary artery bypass grafts were anesthetized with sufentanil and a propofol target controlled infusion $(2.0 \mu \mathrm{g} / \mathrm{mL})$. Depth of hypnosis was monitored using the bispectral index. Blood samples were collected from the induction of anesthesia up to 12 hours after the end of propofol infusion, at predetermined intervals. Plasma propofol concentrations were measured using high-performance liquid chromatography, followed by a non-compartmental propofol pharmacokinetic analysis. Data were analyzed using ANOVA, considering $p<0.05$ as significant.

RESULTS: After cardiopulmonary bypass, despite similar plasma propofol concentrations in both groups, bispectral index values were lower in the on-pump coronary artery bypass graft group. Time to extubation after the end of propofol infusion was greater in the on-pump coronary artery bypass graft group (334 \pm 117 vs. $216 \pm 85 \mathrm{~min}, \mathrm{p}=0.04)$. Patients undergoing cardiopulmonary bypass had shorter biological $(1.82 \pm 0.5$ vs. $3.67 \pm 1.15 \mathrm{~h}, \mathrm{p}<0.01)$ and terminal elimination $(6.27 \pm 1.29$ vs. $10.5 \mathrm{~h} \pm 2.18, \mathrm{p}<$ $0.01)$ half-life values, as well as higher total plasma clearance $(28.36 \pm 11.40 \mathrm{vs} .18 .29 \pm 7.67 \mathrm{~mL} / \mathrm{kg} / \mathrm{min}, \mathrm{p}=0.03)$, compared to patients in the off-pump coronary artery bypass graft group.

CONCLUSION: Aside from the increased sensitivity of the brain to anesthetics after cardiopulmonary bypass, changes in propofol pharmacokinetics may contribute to its central nervous system effects.

KEYWORDS: Propofol; Target controlled infusion; Pharmacokinetics; Pharmacodynamics; Coronary surgery; Cardiopulmonary bypass.

\section{INTRODUCTION}

Continuous infusion of propofol using a targetcontrolled infusion system (TCI) ${ }^{1}$ facilitates rapid arousal

\footnotetext{
' Serviço de Anestesiologia e Terapia Intensiva Cirúrgica, Instituto do Coração (InCor), Hospital das Clínicas da Faculdade de Medicina da Universidade de São Paulo - São Paulo/SP, Brazil.

II School of Pharmaceutical Science, University of São Paulo - São Paulo/ SP, Brazil.

III Department of Anesthesiology and Pain Management, University of Texas Southwestern Medical Center - Dallas/TX, United States.

Tel.: 55113069.6365

Email: navajasbarbosa@superig.com.br

Received for publication on September 18, 2008

Accepted for publication on December 05, 2008
}

and early tracheal extubation after cardiac surgery, ${ }^{2}$ which may contribute to reduced postoperative mechanical ventilation time, shortened length of stay in the intensive care unit and lower hospital costs. On the other hand, use of cardiopulmonary bypass (CPB) during cardiac surgery has been shown to alter the plasma drug concentration, ${ }^{3,4}$ drugprotein binding, ${ }^{5}$ and brain sensitivity to some anesthetics, ${ }^{6}$ resulting in increased residual postoperative hypnosis and an extended duration of mechanical ventilation. Hemodilution, hypothermia, reduction in hepatic blood, and impairment of hepatic high-extraction drug clearance ${ }^{7}$ have been proposed as mechanisms that may underlie CPB alterations of drug pharmacokinetics (PK) and pharmacodynamics (PD). 
CPB-induced alterations in propofol PK have been described in patients undergoing cardiac surgery. ${ }^{8-12}$ Hiraoka et al. found that the fraction of unbound propofol in blood increased by two-fold during cardiopulmonary bypass. ${ }^{8}$ Hammaren et al. observed that, during CPB, the unbound propofol concentration did not change, but auditory evoked potential latency was prolonged compared with baseline values measured after the induction of anesthesia and before the start of CPB. ${ }^{12}$ Takizawa et al. reported that the anesthetic effect of propofol significantly increased during CPB, without any alteration in the total drug concentration. ${ }^{5}$

While CPB-induced propofol PK alterations have been the subject of several studies, there have been no investigations comparing CPB-induced alterations in propofol PK-PD to a control group of patients undergoing cardiac surgery without $\mathrm{CPB}$. This study was designed to test the hypothesis that changes in the PK of propofol increase its hypnotic effects after $\mathrm{CPB}$, as evaluated by changes in bispectral index (BIS) values.

\section{METHODS}

The study protocol was approved by the Hospital Committee at the University of São Paulo and is in accordance with the Helsinki Declaration; written informed consent was obtained from each patient. Twenty patients aged between 52-75 years with left ventricular ejection fractions $>50 \%$ and normal hepatic function who were scheduled for elective coronary artery surgery were selected for this study. The patients were assigned to either the onpump coronary artery bypass graft $(\mathrm{CABG} n=10)$ or offpump coronary artery bypass (OPCAB $n=10)$ surgery group based on the anatomical characteristics of the coronary arteries. A single surgical team operated on all patients.

Pre-anesthetic medication consisted of midazolam $0.2 \mathrm{mg} / \mathrm{kg}$ administered orally $30 \mathrm{~min}$ before surgery, with a maximum dose of $15 \mathrm{mg}$. After cardiovascular monitoring, a specific intravenous line was inserted in the right arm for propofol infusion. General anesthesia was induced using sufentanil $(0.5 \mu \mathrm{g} / \mathrm{kg})$, pancuronium $(0.1 \mathrm{mg} / \mathrm{kg})$ and propofol TCI (Diprivan ${ }^{\mathrm{R}}$, Astra-Zeneca, Rueil-Malmaison, France) to achieve a predicted plasma concentration of $2.0 \mu \mathrm{g} / \mathrm{mL}$ in 30 seconds through a propofol infusion device (Diprifusor ${ }^{\mathrm{R}}$, Astra-Zeneca, Detroit, USA), according to Marsh's pharmacokinetic model ${ }^{13}$. Anesthesia was maintained by continuous infusion of sufentanil $\left(0.5 \mu \mathrm{g} \cdot \mathrm{kg}^{-1} \cdot \mathrm{h}^{-1}\right)$ and propofol TCI to maintain a predicted plasma concentration of $2 \mu \mathrm{g} / \mathrm{mL}$.

After tracheal intubation, mechanical ventilation was initiated using a Cicero ventilator (Drägger, Lubeck, Germany) with a tidal volume of $8 \mathrm{~mL} / \mathrm{kg}$, respiratory frequency of 12 breaths per minute, I:E ratio of 1:2, inspired oxygen fraction of 0.6 and $5 \mathrm{~cm} \mathrm{H}_{2} \mathrm{O}$ PEEP. Patients in the OPCAB group received an intravenous dose of heparin, 100 $\mathrm{UI} / \mathrm{kg}$, before the beginning of anastomosis, and the CABG group received $400 \mathrm{UI} / \mathrm{kg}$ of heparin before the initiation of $\mathrm{CPB}$. After initiation of $\mathrm{CPB}$ using a centrifugal pump and a membrane oxygenator primed with $1500 \mathrm{~mL}$ of Lactated Ringer Solution and $250 \mathrm{~mL}$ of mannitol $20 \%$, patients were cooled to a core temperature of $32-34^{\circ} \mathrm{C}$. This temperature was maintained until the end of the grafting procedure. Upon rewarming to $37^{\circ} \mathrm{C}$, the patients were weaned from $\mathrm{CPB}$. Vasoactive drugs were infused to manage hemodynamic instability when judged necessary by the attending anesthesiologist.

Brain activity was continuously monitored by use of the BIS monitor (BIS ${ }^{R}$ XP, Aspect Medical Systems, Natick, MA) from admission to the operating room until $12 \mathrm{~h}$ after tracheal extubation. BIS values were collected as an average of recordings taken over a $60 \mathrm{~s}$ interval when each arterial blood sample was obtained for determination of the plasma propofol concentration.

The predicted plasma propofol concentration of $2 \mu \mathrm{g} / \mathrm{mL}$ was maintained throughout surgery, using the TCI delivery system and monitoring of blood samples $(3 \mathrm{~mL})$ that were drawn from the arterial catheter at $0,5,15,30,60,120$ and 240 min intervals after the induction of anesthesia. In the CABG group, additional blood samples were collected immediately prior to the initiation of CPB and at 5, 15, 30 and $60 \mathrm{~min}$ after the initiation of bypass, as well as upon discontinuation of CPB. At the end of surgery, the propofol TCI was reduced from $2 \mu \mathrm{g} / \mathrm{mL}$ to $1 \mu \mathrm{g} / \mathrm{mL}$; samples were collected at $0,5,15,30,60,120$ and 240 min after onset. When tracheal extubation was clinically indicated, the propofol TCI was discontinued, and blood samples were subsequently collected at $0,5,15,30,60,120,240,480$ and 720 min. All blood samples were drawn into glass tubes containing sodium EDTA.

The criteria for tracheal extubation were: 1) hemodynamic stability (i.e., normal arterial pressure, central venous saturation $>70 \%$, heart rate $<120 / \mathrm{min}$, no signs of myocardial ischemia); 2) adequate pulmonary function (i.e., $\mathrm{PaO}_{2}>80$ $\mathrm{mm} \mathrm{Hg}$ and $\mathrm{PaCO}_{2}<45 \mathrm{~mm} \mathrm{Hg}$ at $\mathrm{FiO}_{2}$ 0.4, spontaneous respiratory rate $<30 / \mathrm{min}$ and tidal volume $>5 \mathrm{~mL} / \mathrm{kg}$, PEEP $=5 \mathrm{~cm} \mathrm{H} \mathrm{H}_{2} \mathrm{O}$ ); 3) good muscle strength (i.e., spontaneous ventilation, ability to lift head); 4) consciousness (i.e., ability to follow simple commands) and 5) absence of surgical complications (i.e., bleeding $<100 \mathrm{~mL}$ within previous 30 minutes). Following extubation, patients were provided with an intravenous patient-controlled analgesia (PCA) system and were able to self-administer $1 \mathrm{mg}$ bolus doses of morphine, as needed. All patients received supplemental oxygen via a face 
mask (flow between 3 and 10 L.min ${ }^{-1}$ ) following extubation to maintain oxygen saturation $>95 \%$.

\section{Pharmacokinetic analysis}

For measurement of plasma propofol concentrations, blood samples were centrifuged at $3000 \mathrm{rpm}$ for $30 \mathrm{~min}$; the plasma was separated and stored in a freezer at $-20^{\circ} \mathrm{C}$. The plasma samples containing propofol were analyzed by high-performance liquid chromatography ${ }^{14,15}$. Validation of the analytical method demonstrated propofol detection and quantification limits of 0.05 and $0.10 \mathrm{mg} / \mathrm{L}$, respectively. Intra- and inter-day precision were 8 and $9 \%$, respectively, and intra- and inter-day accuracy were 92 and 93\%, respectively.

Pharmacokinetic parameters were calculated in the post-CPB period using the plasma drug concentration measured during the $12 \mathrm{hr}$ observation period after stopping the propofol infusion, using PK-Solutions 2.0 noncompartmental pharmacokinetics data analysis software (Ashland, OH). The groups were compared with respect to: distribution rate hybrid constant $(\alpha)$, distribution halflife $\left(\mathrm{T}_{1 / 2} \alpha\right)$, fast elimination rate constant $(\beta)$, biological half-life $\left(\mathrm{T}_{1 / 2} \beta\right)$, slow elimination rate constant $(\gamma)$, terminal elimination half-life $\left(\mathrm{T}_{1 / 2} \gamma\right)$, total plasma clearance $\left(\mathrm{CL}_{\mathrm{T}}\right)$, volume of distribution beta $(\mathrm{Vd} \beta)$ and volume of distribution gamma $(\mathrm{Vd} \gamma)$. Since the interval from the beginning of surgery to tracheal extubation differed among patients, the software estimated plasma propofol concentrations for specific time points in order to permit inter-patient comparisons.

Postoperative bispectral index values were plotted against simultaneous plasma propofol concentration measurements and PK-PD modeling was applied to both groups using GraphPad Prism for Windows v.3.0 software (GraphPad Software Inc., San Diego, CA). A sigmoid $\mathrm{E}_{\mathrm{MAX}}$ model was chosen to represent the hypnotic effect of propofol (i.e., BIS values) as a function of the measured plasma concentration. This PK-PD model is represented by the following equation:

$Y=E_{\text {MAX }}+\frac{\left(E_{0}-E_{M A X}\right) X^{h}}{E C 50^{h}+X^{h}}$

Where " $\mathrm{X}$ " is the concentration of propofol and " $Y$ " is the response. "Y" starts at the top $\left(\mathrm{E}_{0}\right.$, the BIS value at baseline) and goes to the bottom ( $\mathrm{E}_{\mathrm{MAX}}$, the minimum BIS noted was considered to be the maximum effect), with a sigmoid shape. The $\mathrm{E}_{\mathrm{MAX}}$, EC50 (concentration of drug required to produce $50 \%$ of maximum drug effect) and h (hill slope) parameters were compared among the investigated patient groups. To evaluate the adaptability of the model, the correlation index " $\mathrm{R}^{2}$ " was applied.
Normal distribution of data was tested using the Kolmogorov-Smirnov test. Demographic and surgical data were compared by means of the unpaired Student's t-test or chi square test, as appropriate. We compared the doses of propofol infused during surgery, the amount infused from the end of surgery to the discontinuation of the propofol infusion immediately prior to tracheal extubation, and the time from the end of propofol infusion until the tracheal extubation between groups by means of the unpaired Student's t-test. Measured plasma propofol concentrations and bispectral index values for the two groups were compared using analysis of variance for repeated measures followed by Wald or Student-Neumann-Keuls post-hoc test, as indicated. Statistical analyses were performed using SPSS for Windows v.8.0 (SPSS Inc., Chicago, IL). The results are reported as mean, 95\% upper and lower confidence limits (95\% CI), and standard error of mean or standard deviation, with $\mathrm{p}$-values $<0.05$ considered statistically significant.

\section{RESULTS}

Table 1 summarizes demographic and surgical data. Age, height, weight, body mass index, duration of surgery and time from the end of surgery to propofol infusion suspension were similar in both groups. The mean length of CPB in the CABG group was $79 \pm 23$ minutes. After discontinuation of propofol infusion, the times to awakening and tracheal extubation were significantly greater in the CABG group.

Dobutamine infusion in doses up to $5.0 \mu \mathrm{g} \cdot \mathrm{kg}^{-1} \cdot \mathrm{min}^{1}$ was required in two patients during weaning from CPB; nitroglycerine was administered to five patients and sodium nitroprusside to four patients after $C P B$. In the OPCAB group, three patients received norepinephrine infusion with doses ranging between $0.01-0.2 \mu \mathrm{g} . \mathrm{kg}^{-1}$ during cardiac tilt. All patients achieved hemodynamic stability in the immediate postoperative period and all vasoactive drugs were discontinued within 24 hours after surgery. The cumulative consumption of morphine in the first $12 \mathrm{hr}$ after the end of the propofol infusion was $7.2 \pm 6.6 \mathrm{mg}$ in the CABG group and $10.6 \pm 8.8 \mathrm{mg}$ in the OPCAB group $(\mathrm{p}=0.36)$.

A total of 520 blood samples were analyzed for plasma propofol concentration in the CABG (290 samples) and OPCAB (230 samples) groups. The groups did not differ with respect to total propofol doses infused during surgery $(1452 \pm 256 \mathrm{mg}$ vs. $1408 \pm 289 \mathrm{mg}$ in the CABG and OPCAB groups, respectively, $\mathrm{p}=0.648$ ), or with respect to the total propofol doses infused from the end of surgery to the time of tracheal extubation $(144 \pm 81 \mathrm{mg}$ vs. $95 \pm 68 \mathrm{mg}$ in the $\mathrm{CABG}$ and $\mathrm{OPCAB}$ groups, respectively, $\mathrm{p}=0.26$ ). The actual plasma propofol concentrations in $\mathrm{CABG}$ and OPCAB groups over time are displayed in figure 1. Plasma propofol 
Table 1 - Demographic, surgical and postoperative data of the patients in both the CABG and OPCAB treatment groups

\begin{tabular}{|c|c|c|c|}
\hline & CABG & OPCAB & $\mathrm{p}$ value \\
\hline Gender (male:female) & 09:01 & 07:03 & 0.26 \\
\hline Age (years) & $62 \pm 8$ & $68 \pm 7$ & 0.07 \\
\hline Body weight $(\mathrm{kg})$ & $75 \pm 11$ & $75 \pm 8$ & 0.93 \\
\hline Height (m) & $1.63 \pm 0.04$ & $1.66 \pm 0.10$ & 0.55 \\
\hline Body mass index & $28 \pm 5$ & $27 \pm 3$ & 0.74 \\
\hline Length of surgery (min) & $278 \pm 54$ & $287 \pm 77$ & 0.75 \\
\hline Time from the end of surgery to end of propofol infusion (min) & $91 \pm 36$ & $64 \pm 31$ & 0.10 \\
\hline Time from the end of propofol infusion to awakening and tracheal extubation (min) & $334 \pm 117$ & $216 \pm 85$ & 0.04 \\
\hline
\end{tabular}

CABG - on-pump coronary artery bypass graft surgery; OPCAB - off-pump coronary artery bypass graft surgery. Data reported as mean \pm standard deviation.

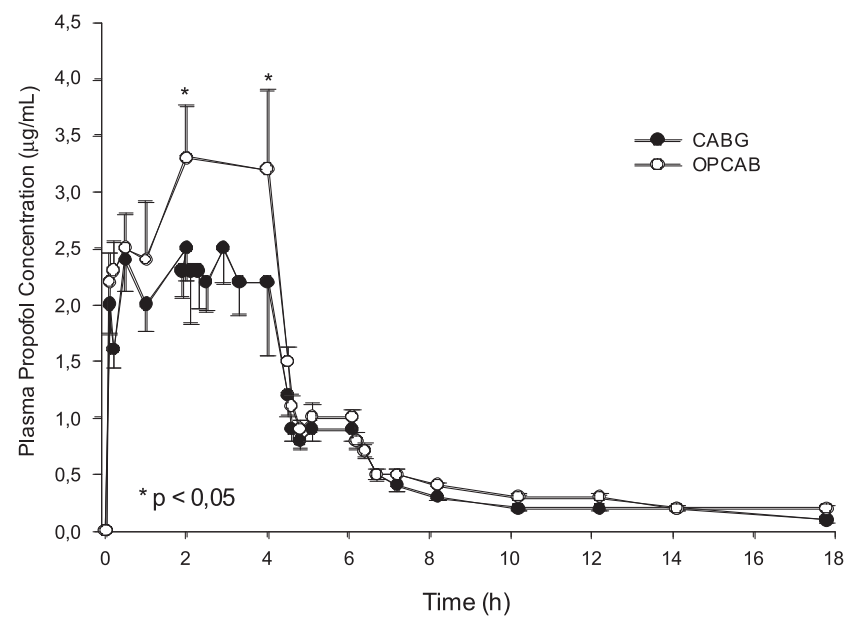

Figure 1 - Plasma propofol concentrations as a function of time after the induction of anesthesia. Closed circles represent the coronary artery bypass graft $(\mathrm{CABG})$ group and open circles represent the off-pump coronary artery bypass $(\mathrm{OPCAB})$ group. Data reported as mean values \pm standard error * $\mathrm{p} \leq 0.05$

concentrations did not differ between the groups throughout the study, except during the moments corresponding to cardiopulmonary bypass in the CPB group, during which the plasma concentration was higher in the OPCAB group. When the propofol PK parameters were analyzed for time points after $\mathrm{CPB}$ up to the time of observation in the $\mathrm{CPB}$ group and for corresponding time points in the $\mathrm{OPCAB}$ group, we observed that the fast elimination rate constant in the CPB group was double that of the OPCAB group $(\mathrm{p}<0.01)$, while the biological half-life was $50 \%$ lower $(\mathrm{p}<0.01)$ (Table 2). Patients undergoing CPB exhibited a higher terminal elimination half-life $(\mathrm{p}<0.01)$ and higher total plasma clearance $(\mathrm{p}<0.01)$ when compared to patients in the OPCAB group. Figure 2 shows plasma propofol concentration measures plotted against respective Bispectral Index values after the end of coronary grafting until the end of blood sampling in both groups.

During the postoperative period, BIS values were
Table 2 - Pharmacokinetic variables for patients undergoing $\mathrm{CABG}$ and $\mathrm{OPCAB}$ procedures

\begin{tabular}{lccc}
\hline Parameter & CABG & OPCAB & p value \\
\hline $\mathrm{a}$ (hour $\left.{ }^{-1}\right)$ & $4.14 \pm 1.53$ & $4.76 \pm 2.96$ & 0.58 \\
\hline $\mathrm{T}_{1 / 2} \mathrm{a}$ (hour) & $0.19 \pm 0.07$ & $0.21 \pm 01770.15$ & 0.71 \\
\hline $\mathrm{b}$ (hour $\left.{ }^{-1}\right)$ & $0.40 \pm 0.10$ & $0.21 \pm 0.06$ & $<0.01$ \\
\hline $\mathrm{T}_{1 / 2} \mathrm{a}$ (hour) & $1.82 \pm 0.5$ & $3.67 \pm 1.15$ & $<0.01$ \\
\hline $\mathrm{g}$ (hour $\left.{ }^{-1}\right)$ & $0.11 \pm 0.02$ & $0.07 \pm 0.01$ & $<0.01$ \\
\hline $\mathrm{T}_{1 / 2} \mathrm{~g}($ hour$)$ & $6.27 \pm 1.29$ & $10.5 \pm 2.18$ & $<0.01$ \\
$\mathrm{CL}_{\mathrm{T}}\left(\mathrm{mL} \mathrm{min}^{-1} \mathrm{~kg}^{-1}\right)$ & $28.36 \pm 11.40$ & $18.29 \pm 7.67$ & 0.03 \\
\hline $\mathrm{Vd}_{\mathrm{b}}\left(\mathrm{L} \mathrm{kg}^{-1}\right)$ & $4.39 \pm 1.90$ & $5.61 \pm 2.69$ & 0.26 \\
\hline $\mathrm{Vd}_{\mathrm{g}}\left(\mathrm{L} \mathrm{kg}^{-1}\right)$ & $15.99 \pm 9.40$ & $16.74 \pm 8.69$ & 0.86 \\
\hline$\alpha=\mathrm{distibut}^{2}$ &
\end{tabular}

$\alpha=$ distribution rate hybrid constant, $T_{1 / 2} \alpha=$ Distribution half-life; $\beta=$ fast elimination rate constant; $\mathrm{T}_{1 / 2} \beta=$ biological half-life; $\gamma=$ slow elimination rate constant; $\mathrm{T}_{1 / 2} \gamma=$ terminal elimination half-life; $\mathrm{CL}_{\mathrm{T}}=$ total plasma clearance; $\mathrm{Vd} \beta=$ volume of distribution beta; $\mathrm{Vd} \gamma=$ volume of distribution gamma. Data are expressed as mean values $\pm \mathrm{SD}$.

significantly higher in the OPCAB group in comparison to the CABG group, as shown in figure 3. PK-PD modeling performed by plotting the BIS values as a function of the plasma concentrations demonstrated hysteresis between the $\mathrm{CABG}$ and OPCAB group curves, as shown in figure 4. For the same plasma propofol concentrations in the wakening period, higher values of BIS are observed in the OPCAB group. Table 3 displays the results of the sigmoid $\mathrm{E}_{\mathrm{MAX}}$ model applied to both groups, with $\mathrm{r}^{2}=0.95$ in the OPCAB group and $r^{2}=0.96$ in the CABG group.

\section{DISCUSSION}

When combined with potent opioid analgesics, propofol infusion provides excellent hemodynamic stability during cardiac surgery and allows for early tracheal extubation in the immediate postoperative period. ${ }^{2,9,16}$ The use of CPB to maintain adequate circulation and tissue perfusion 


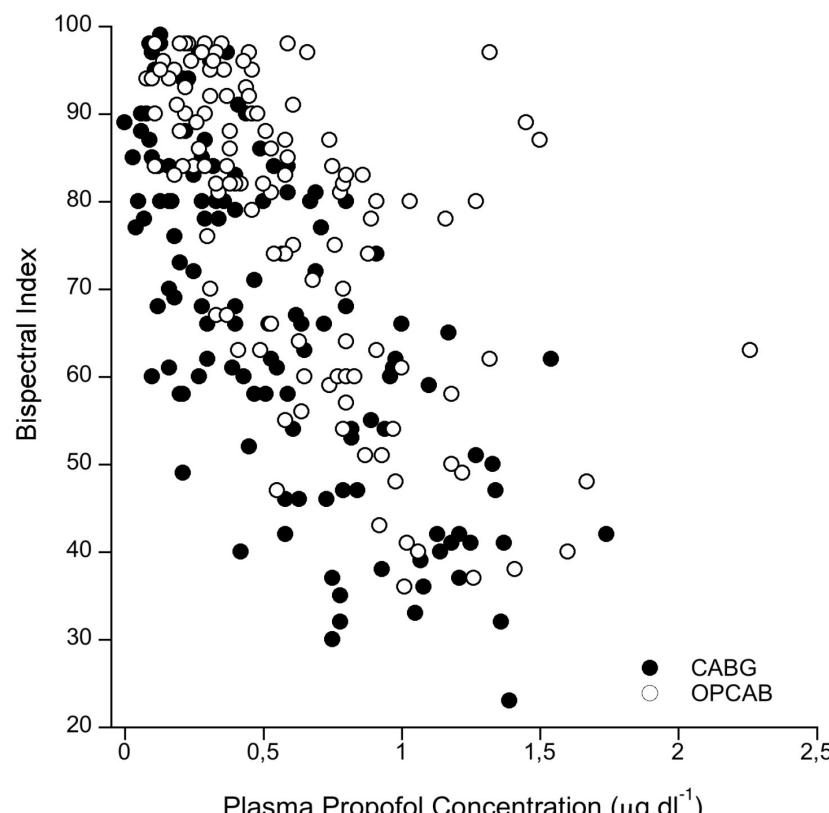

Figure 2 - Plasma propofol concentration measures plotted against respective bispectral index values after the end of coronary grafting up to the end of blood sampling. Closed circles represent the coronary artery bypass graft (CABG) group and open circles represent the off-pump coronary artery bypass $(\mathrm{OPCAB})$ group

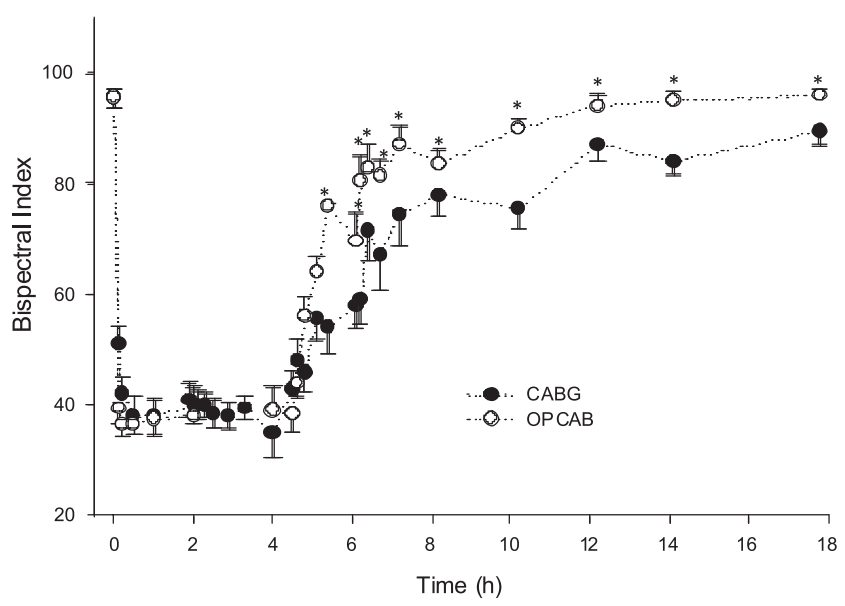

Figure 3 - Time course of changes in bispectral index (BIS) values. Closed circles represent coronary artery bypass graft (CABG) group and open circles represent off-pump coronary artery bypass (OPCAB) group. After discontinuation of the propofol infusion, time " 0 " represents the point at which the BIS values were higher in the OPCAB group as compared to the CABG group. Data reported as mean \pm standard error $* \mathrm{p}<0.01$

during coronary graft, on the other hand, is known to alter the pharmacokinetics and pharmacodynamics of several anesthetic drugs, thus increasing their central nervous system depressant effects. ${ }^{4,17}$ Although the alterations induced by CPB on propofol pharmacokinetics are well documented, no studies have compared these effects of CPB on propofol pharmacokinetics to a control group undergoing the same procedure without $\mathrm{CPB}$ in the context of impact on arousal and time to extubation.

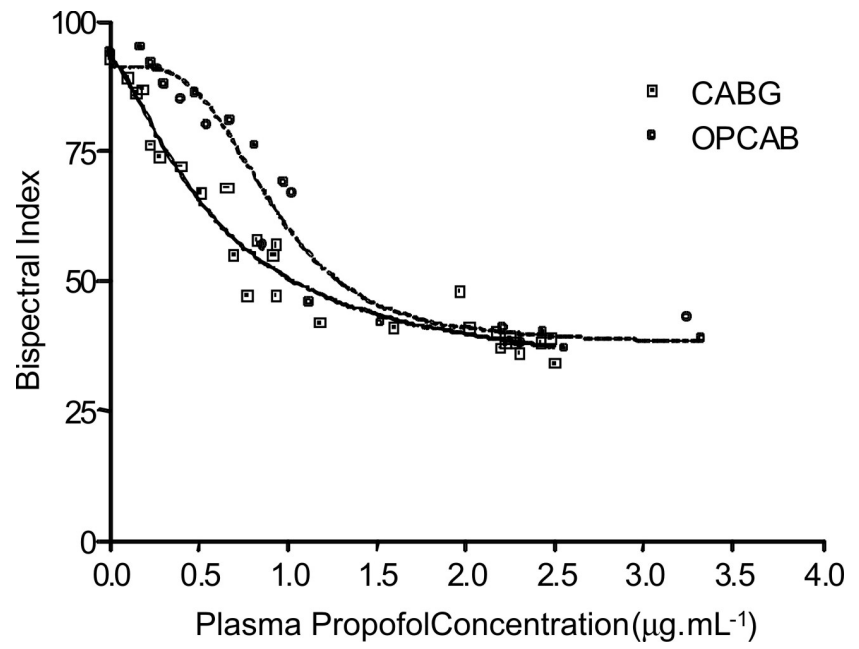

Figure 4: Pharmacokinetic-pharmacodynamic modeling using sigmoid $\mathrm{E}_{\mathrm{MAX}}$ model of plasma propofol concentration and bispectral index (BIS) values during and after surgery

Table 3 - Pharmacokinetic-pharmacodynamic modeling using bispectral index (BIS) values and plasma propofol concentrations in the $\mathrm{CABG}$ and $\mathrm{OPCAB}$ treatment groups

\begin{tabular}{lcc}
\hline \multicolumn{3}{c}{ Sigmidal $\mathrm{E}_{\mathrm{MAX}}$ model } \\
\hline & $\begin{array}{c}\text { CABG } \\
\text { (Mean }(95 \% \mathrm{CI})\end{array}$ & $\begin{array}{c}\text { OPCAB } \\
\text { (Mean }(95 \% \mathrm{CI})\end{array}$ \\
\hline Best-fit values & & \\
Emax (minimum BIS value) & $30.4(20.0$ to 40.8$)$ & $38.0(32.1$ to 43.9$)$ \\
Baseline (BIS) & $93(86$ to 100$)$ & $92(86$ to 97$)$ \\
Hillslope & $1.4(0.8$ to 2.1$)$ & $3.6(1.6$ to 5.6$)$ \\
EC50 $\left(\mathrm{mg} \mathrm{L}^{-1}\right)$ & $06(0.4$ to 0.8$)$ & $0.9(0.8$ to 1.0$)$
\end{tabular}

Goodness of fit

$\begin{array}{lll}\mathrm{R}^{2} & 0.96 & 0.95\end{array}$

Emax: concentration of drug required to produce maximum effect; EC50: concentration of drug required to produce $50 \%$ of maximum effect; . CABG - coronary artery bypass graft surgery; OPCAB - off-pump coronary artery bypass graft surgery

In this study, we observed that plasma propofol concentrations were similar in both groups throughout the surgery and recovery period when the same infusion regimen was applied by means of TCI, except during coronary grafting, when significantly lower concentrations were measured in the $\mathrm{CABG}$ group. After the end of $\mathrm{CPB}$, despite similar plasma propofol concentrations, BIS values remained lower in the CABG group and time to extubation was greater after the interruption of propofol infusion . Nonetheless, the total amount of infused propofol was equivalent in both groups (1408 $\pm 289 \mathrm{mg}$ versus $1452 \pm 256 \mathrm{mg}$ ); the PK-PD modeling demonstrated comparable maximal BIS effects $\left(\mathrm{E}_{\mathrm{MAX}}\right)$ in the OPCAB and CABG groups (30.4 versus 38.0); and the EC50 was reduced by $33 \%$ in patients undergoing 
CPB when compared to patients submitted to off-pump surgery. Taken together, these findings suggest an enhanced sensitivity to propofol in patients undergoing CPB. This hypothesis is supported by published studies that reported similar results in patients receiving propofol during and after $\mathrm{CPB}$. Yoshitani et al. reported that, during normothermic $\mathrm{CPB}$, the burst suppression rate gradually increased in response to three fixed dose regimens of 4, 5 and $6 \mathrm{mg} . \mathrm{kg}$ ${ }^{1} \cdot \mathrm{h}^{-1}$ during CPB compared to baseline ${ }^{18}$. Takizawa et al. reported that the anesthetic effect of propofol increased significantly during CPB without any alteration in the total drug concentration. ${ }^{5}$ This mechanism has already been validated for volatile anesthetics in experimental models ${ }^{19,20}$ and clinical contexts, ${ }^{6,17}$ where the minimum alveolar concentration (MAC) was decreased after CPB.

Upon first glance, these findings could be entirely attributed to the increased sensitivity of the brain to propofol after CPB. Nevertheless, the pharmacokinetics of propofol were significantly modified by $\mathrm{CPB}$, and this alteration could contribute to the increased central nervous system depressant effects observed in the CABG group postoperatively. Propofol elimination was found to be biphasic; the fast elimination and slow elimination rate constants were higher in the CABG group than in the OPCAB group, while fast and slow elimination half-life values were lower. Furthermore, total propofol plasma clearance was significantly higher in the CPB group. These alterations in pharmacokinetics suggest that there is an increase in the unbound fraction of propofol in blood after CPB and that more drug is available for clearance from the circulation during a given unit of time. If the binding of propofol to plasma proteins is reduced, the availability of free drug at the site of action is also greater, contributing to the more intense central nervous system depressant effect observed in the CABG group.

In fact, it is known that $\mathrm{CPB}$ may lead to a reduction in the amount of plasma protein that binds to several drugs, including propofol. Our findings support those reported by Hiraoka et al., who observed that the fraction of unbound propofol in blood increased by two-fold during cardiopulmonary bypass. ${ }^{8}$ The same group also reported that the total concentration of propofol in blood using doses of either 4 or $6 \mathrm{mg} \cdot \mathrm{kg}^{-1} \cdot \mathrm{h}^{-1}$ remained unchanged after the initiation of $\mathrm{CPB}$, when compared to pre-CPB plasma concentration values in both groups; however, the fraction of unbound propofol in blood doubled during CPB. ${ }^{5}$ Dawson et al also reported that $\mathrm{CPB}$ caused a reduction in total propofol plasma concentrations, while unbound concentrations remained stable. ${ }^{21}$ Unfortunately, we did not measure the fraction of circulating unbound plasma propofol. However, based on the indirect pharmacokinetic data found in this study and on the strength of the evidence from the literature, we maintain that $\mathrm{CPB}$-induced alterations in propofol pharmacokinetics play a significant role in its increased postCPB hypnotic effects.

It could be argued that the concomitant use of sufentanil may confound the BIS evaluation in the CABG group, despite the fact that the infusion rate was the same for both groups throughout the operation. Lysakowki et al. studied the effects of opioids on loss of consciousness and BIS values during propofol induction of anesthesia and concluded that sufentanil produced minimal electrophysiological alterations in the central nervous system. ${ }^{22}$ In addition, Hudson et al. reported that CPB had clinically insignificant effects on sufentanil kinetics in adults. ${ }^{23}$ According to these studies, we can exclude any significant effect of $\mathrm{CPB}$ on sufentanil $\mathrm{PK}$. The association of the two mechanisms may explain the differences between the groups in terms of the propofol pharmacodynamics: a) increased brain sensitivity to propofol and b) extensively altered post-CPB propofol pharmacokinetics, leading to an increase in unbound propofol in blood plasma.

This study has some limitations. The propofol infusion device Diprifusor ${ }^{\mathrm{R}}$ (Astra-Zeneca, Detroit, USA) used in the study is based on Marsh's pharmacokinetic model, ${ }^{13}$ which does not take into account intraoperative physiologic alterations, such as hemodilution and hypothermia, or changes in drug-protein binding. Despite the well-known limitations of propofol administration using this model, ${ }^{24}$ it has been successfully used in cardiac surgery. ${ }^{2}$ Since measured plasma propofol concentrations were used in PKPD analysis instead of the plasma concentrations predicted from Marsh's model (as in the great majority of studies), and given that the plasma concentrations were very similar in both groups after CPB, we can assume that the use of Diprifusor $^{\mathrm{R}}$ did not interfere with the results of the study.

Another limitation of this study is the fact that the surgical approach was defined on the day of the surgery by the senior surgeon based on the anatomical characteristics of the coronary arteries. In some cases, the decision was changed intraoperatively. This method prohibited use of a random preordered group assignment. However, since all patients were operated upon by a single surgical team and possessed similar demographic and physiologic characteristics, this selection bias is likely minimal.

In conclusion, despite the increased brain sensitivity to propofol after $\mathrm{CPB}$, the difference in hypnotic effects after $\mathrm{CPB}$ when compared to an adequate control group undergoing the same surgery without $\mathrm{CPB}$ results from changes in its pharmacokinetics.

Financial Support: Zerbini Foundation and FAPESP (Fundação de Amparo à Pesquisa do Estado de São Paulo)

Clinical Trials Registration Number: NCT00622791 


\section{REFERENCES}

1. White PF. Intravenous anesthesia and analgesia: what is the role of target-controlled infusion? J Clin Anesth. 1996;8:26S-28S.

2. Olivier P, Sirieix D, Dassier P, D'Attellis N, Baron JF. Continuous infusion of remifentanil and target-controlled infusion of propofol for patients undergoing cardiac surgery: a new approach for scheduled early extubation. J Cardiothorac Vasc Anesth. 2000;14:29-35.

3. Holley FO, Ponganis KV, Stanski DR. Effect of cardiopulmonary bypass on the pharmacokinetics of drugs. Clin Pharmacokinet. 1982;7:23451 .

4. Mets B. The pharmacokinetics of anesthetic drugs and adjuvants during cardiopulmonary bypass. Acta Anaesthesiol Scand. 2000;44:261-73.

5. Takizawa E, Hiraoka H, Takizawa D, Goto F. Changes in the effect of propofol in response to altered plasma protein binding during normothermic cardiopulmonary bypass. Br J Anaesth. 2006;96:17985 .

6. Lundell JC, Scuderi PE, Butterworth JFt. Less isoflurane is required after than before cardiopulmonary bypass to maintain a constant bispectral index value. J Cardiothorac Vasc Anesth. 2001;15:551-4.

7. Buylaert WA, Herregods LL, Mortier EP, Bogaert MG. Cardiopulmonary bypass and the pharmacokinetics of drugs. An update. Clin Pharmacokinet 1989; 17:10-26.

8. Hiraoka H, Yamamoto K, Okano N, Morita T, Goto F, Horiuchi R. Changes in drug plasma concentrations of an extensively bound and highly extracted drug, propofol, in response to altered plasma binding. Clin Pharmacol Ther.004;75:324-30.

9. Bailey JM, Mora CT, Shafer SL. Pharmacokinetics of propofol in adult patients undergoing coronary revascularization. The Multicenter Study of Perioperative Ischemia Research Group. Anesthesiology. 1996;84:1288-97.

10. Lee HS, Khoo YM, Chua BC, Ng AS, Tan SS, Chew SL. Pharmacokinetics of propofol infusion in Asian patients undergoing coronary artery bypass grafting. Ther Drug Monit. 1995;17:336-41

11. Massey NJ, Sherry KM, Oldroyd S, Peacock JE. Pharmacokinetics of an infusion of propofol during cardiac surgery. Br J Anaesth. 1990;65:4759.

12. Hammaren E, Yli-Hankala A, Rosenberg PH, Hynynen M. Cardiopulmonary bypass-induced changes in plasma concentrations of propofol and in auditory evoked potentials. Br J Anaesth. 1996;77:3604.
13. Marsh B, White M, Morton N, Kenny GN. Pharmacokinetic model driven infusion of propofol in children. Br J Anaesth. 1991;67:41-8.

14. Yeganeh MH, Ramzan I. Determination of propofol in rat whole blood and plasma by high-performance liquid chromatography. J Chromatogr B Biomed Sci Appl. 1997;691:478-82.

15. Knibbe CA, Koster VS, Deneer VH, Stuurman RM, Kuks PF, Lange R. Determination of propofol in low-volume samples by high-performance liquid chromatography with fluorescence detection. J Chromatogr B Biomed Sci Appl. 1998;706:305-10.

16. Mora CT, Dudek C, Torjman MC, White PF. The effects of anesthetic technique on the hemodynamic response and recovery profile in coronary revascularization patients. Anesth Analg. 1995;81:900-10.

17. Yang H, Homi HM, Smith BE, Grocott HP. Cardiopulmonary bypass reduces the minimum alveolar concentration for isoflurane. $\mathrm{J}$ Cardiothorac Vasc Anesth. 2004;18:620-3.

18. Yoshitani K, Kawaguchi M, Takahashi M, Kitaguchi K, Furuya H. Plasma propofol concentration and EEG burst suppression ratio during normothermic cardiopulmonary bypass. Br J Anaesth. 2003;90:122-6.

19. Hall RI, Poole L, Murphy JT, Moffitt EA. A randomized study of changes in serum cholesterol, triglycerides, high density lipoproteins, and cortisol during cardiac surgery in patients anaesthetised with propofol-sufentanil vs enflurane-sufentanil. Cardiac Anaesthesia Research Group. Can J Anaesth. 1990;37: S76.

20. Neumeister MW, Li G, Williams G, Doak G, Sullivan JA, Hall RI Factors influencing MAC reduction after cardiopulmonary bypass in dogs. Can J Anaesth. 1997;44:1120-6.

21. Dawson PJ, Bjorksten AR, Blake DW, Goldblatt JC. The effects of cardiopulmonary bypass on total and unbound plasma concentrations of propofol and midazolam. J Cardiothorac Vasc Anesth. 1997;11:55661.

22. Lysakowski C, Dumont L, Pellegrini M, Clergue F, Tassonyi E. Effects of fentanyl, alfentanil, remifentanil and sufentanil on loss of consciousness and bispectral index during propofol induction of anaesthesia. $\mathrm{Br} \mathrm{J}$ Anaesth. 2001; 86:523-7.

23. Hudson RJ, Thomson IR, Jassal R. Effects of cardiopulmonary bypass on sufentanil pharmacokinetics in patients undergoing coronary artery bypass surgery. Anesthesiology. 2004;101:862-71.

24. Barakat AR, Sutcliffe N, Schwab M. Effect site concentration during propofol TCI sedation: a comparison of sedation score with two pharmacokinetic models. Anaesthesia. 2007;62:661-6. 
